\title{
LOS PASOS PERDIDOS. ESCRITOS DE GAOS SOBRE ORTEGA, POR JOSÉ LASAGA*
}

\author{
Javier San Martín \\ Universidad Nacional de Educación a Distancia- UNED \\ jsan@fsof.uned.es
}

Me produce mucha satisfacción participar en esta mesa por muchas razones, entre las cuales no es la menor compartir un buen rato con amigos y tener la oportunidad de saludarles ya a punto de terminar este año de trabajo tan intenso que hemos tenido todos.

Además, para mostrar en público mi más sincero reconocimiento por esta publicación, absolutamente necesaria. Quiero tocar, siempre con la brevedad requerida para no resultar pesado, tres puntos más o menos conectados entre sí.

* Editorial Biblioteca Nueva, Madrid, 1913. Este texto fue leído, en diciembre de 2013, en la sesión de presentación del libro editado por el profesor Lasaga. Desde entonces, hasta ahora, han pasado unos años, pero este escrito sigue teniendo oportunidad, sobre todo porque está ya próximo a salir el tomo I de las Obras completas de Gaos, que incluye los textos que el filósofo hispano-mexicano escribió antes de ir a México, por tanto, hasta sus 38 años y que, de estar previsto publicarlo en un volumen, parece que será necesario desdoblar el tomo en dos volúmenes. Por otro lado, en este escrito hay una apreciación sobre la filosofía de Gaos que enmarca esos escritos. 
En el primero mostraré las razones de la oportunidad de esta publicación y, por tanto, el necesario agradecimiento a quienes la han hecho posible.

En segundo lugar, me centraré en el prólogo del profesor Lasaga, que creo que merece ser comentado. En tercer término y ya ayudados por lo que nos dice nuestro autor, haré un pequeño recorrido por esos textos, comentando las variaciones de la actitud de Gaos, y aportando algunas observaciones, que no son sino apuntes para un estudio, que personalmente me gustaría hacer, sin que pueda prometer que lo llevaré a cabo, pero dejando por si algún entusiasta quiere adelantarse y lo hace.

\section{OPORTUNIDAD DE ESTA PUBLICACIÓN}

Los textos de Gaos sobre Ortega son de un extraordinario interés y, sin embargo, si miran las bibliografías usuales en cualquiera de nuestras monografías sobre Ortega, Gaos prácticamente está ausente.

¿Por qué digo que son muy interesantes? Porque es posiblemente el primero que trata del periodizar a Ortega. Casi todos los intentos que hemos hecho después de leer a Ortega desde los diversos desarrollos de su obra, y así lo hemos citado numerosísimas veces, empezamos por la periodización de Ferrater Mora, que es la más citada. Pero esa periodización proviene de un libro escrito en 1956, que yo sepa de su libro Ortega y Gasset: an outline of philosophy, de la Universidad de Cambrigde, Inglaterra, que después traduce y publica en Barcelona en 1958, con el título Ortega y Gasset: etapas de una filosofía. La periodización de Gaos, que procede de su primer escrito sobre las profecías, es de 1946 y 1947, fechas en que en España no creo que Gaos fuera un autor legible, en todo caso no creo que fuera un autor de acceso fácil.

Luego vienen los artículos escritos en torno a la muerte de Ortega, que son cuatro, en los que, desde un aire de reconocimiento y afecto por Ortega, asume y profundiza en la periodización. Esos artículos, publicados todos en revistas, no son apenas citados en España, por no decir, en absoluto citados por los orteguianos, seguramente por desconocidos. Hay que tener en cuenta que esas revistas mexicanas difícilmente llegarían a España en esos años de dictadura, siendo escritos por un exiliado republicano como José Gaos. En realidad, hasta la publicación de las Obras completas de Gaos, esos artículos han permanecido en un lamentable y considerable desconocimiento. 
Una vez emprendida la publicación de esas Obras completas, ya podríamos pensar que cambia la situación, pero la discontinuidad de esa publicación tampoco permite hacerse una idea cabal, casi diría que en cierta medida nos pasa desapercibida. De hecho, el tomo IX, en el que están los textos que he aportado, se publicó en 1992. Pero que yo sepa no fueron textos citados. José Lasaga debió de leer "La profecía en Ortega", porque fue él el que me comentó esa anécdota que cuenta Gaos de que él le dijo a Ortega que su filosofía estaba más en Meditaciones del Quijote que en El tema de nuestro tiempo, tema que aparece en La profecía.

Pero de los cuatro interesantísimos artículos apenas hay citas. Y ya, los comentarios, también muy importantes, de las obras póstumas de Ortega, escritos en un tono muy distinto de los anteriores, no se publican hasta 1999 en el tomo $X$ de las Obras completas, con lo que la discontinuidad de la recepción también es muy grande. De estos prácticamente no tenemos nada, y es que recibir las Obras completas no ha sido tarea fácil. Yo he tenido la suerte de que me las ha ido mandando Antonio Zirión, porque de lo contrario, con las de la Biblioteca no habríamos podido manejarlas, porque ahora estamos varios metidos en el estudio de Gaos.

Pues dada esta situación, el que se haya publicado esta recopilación, Ilena un hueco para nosotros tremendamente llamativo. Por el inmenso interés de esta obra y la disponibilidad que de ella nos ofrece. En adelante esta recopilación figurará ya en todas las monografías sobre Ortega, y las periodizaciones que hace Gaos serán tema de discusión de todos nosotros.

Por tanto, no podemos menos de agradecer, primero, al profesor Lasaga la idea de la edición, y después a la Fundación Ortega/Marañón y a Biblioteca Nueva, representada aquí por su director, Antonio Roche, la edición. Gracias a todos ellos disponemos fácilmente de este material que nos facilita infinito el trabajar estos textos que nos dan una muy importante visión sobre Ortega.

\section{LA PRESENTACIÓN DE JOSÉ LASAGA}

Entre nosotros Gaos es un desconocido o sigue siendo casi un desconocido. Por suerte, en los últimos años empezamos a tener una visión de él, pero no deja 
de ser aún muy fragmentaria. Ahora, la edición que se hizo, en su Asturias natal, de las Confesiones profesionales, da un mejor conocimiento, y poco a poco nos vamos familiarizando con su obra. También la antología de Alejandro Rossi, en la editorial Crítica, fue muy importante, pero esa editorial desapareció y con ella la antología. Yo escribí un artículo publicado ahora en el Boletín de la fundación Mindán Manero en el que tomo a Ortega y a Gaos como los que nos muestran el camino que debemos seguir, en mi caso, sabiendo dónde debo desviarme, pero la precisión del camino es genial, y por eso me permite saber exactamente en qué coincido, en qué discrepo y por qué.

Pues bien, el prólogo de J. Lasaga es un alarde de concisión para presentar a Gaos como filósofo, a Gaos en su relación con Ortega, y a Gaos como comentarista de Ortega. Poco más se puede decir, ni mejor en tan poco espacio. La visión que de esas cuarenta y cuatro páginas se saca de Gaos es muy buena, tanto de la problematicidad de la obra de Gaos, como de lo que supone esa fecha fatídica, del primer infarto, al decidir Gaos la necesidad de presentar por fin su propia filosofía. Y luego volveré sobre ello.

Quiero subrayar un punto muy interesante. El profesor Lasaga ha buceado en el tomo XIX, en el que se publica el epistolario de Gaos y ha encontrado alguna carta muy significativa, cuyo contenido puede marcar algunas pautas de la comprensión que Gaos tiene sobre Ortega, y que Gaos se la forma muy temprano, y que luego, quizás por la admiración respecto al maestro con el que mantiene una relación muy fluida y continua, se desactiva esa opinión, pero vuelve a aparecer a partir de la fecha de 1958.

El otro punto que quería comentar de la presentación es la réplica que me da a una opinión mía expuesta en el artículo citado. Yo reprocho a Gaos no haber entendido qué era la subjetividad trascendental husserliana, que somos cada uno de nosotros y por eso es personal; como no entendió eso, no pudo unir la expresión de las necesidades - necesidad no como lo que vuelve, como se dice en alemán, lo notwendig, idea de lo periódico, sino idea de lo que no cesa, lo continuo, como se dice en latín - con la idea de la filosofía como saber común, que descubre lo que Husserl llama los "sólidos vínculos" que se nos imponen a la subjetividad fáctica que somos cada uno de nosotros, y que hace que superemos el carácter de la filosofía como confesión. La forma de entender la subjetividad que tiene Gaos, como pura contingencia, nos lleva a la filosofía como mera y pura literatura. Y discrepo en la valoración de esa actualidad de Gaos por esa idea, 
que, sí, es actual, pero porque Gaos se adelantó a la actual derrota del pensamiento que se da en muchos y que llevaría, en mi opinión, a la desaparición de la filosofía.

Estamos, con esto llegando, ayudados por la mediación de Gaos, al núcleo de la filosofía como problema y, a través de ella, el núcleo de la situación social de la filosofía, porque si la filosofía es confesión profesional, en mi opinión sobraría como profesión y creo que la sociedad política lo entiende muy bien así. El abandono de Gaos por parte de sus alumnos no dejar de ser premonitorio de una forma derrotista de hacer filosofía, que lleva a su desaparición por inútil como profesión. Y lo dejo ahí como una pregunta de un debate que deberemos tener, y que estamos teniendo, y del que Gaos nos marca, como he dicho al principio, claramente la senda, en mi opinión, no para seguirla sino para evitarla, diciendo, por supuesto, que en muchos de los textos de Gaos hay un ejercicio de la filosofía que no se dejaría encuadrar en esa filosofía de la filosofía, por ejemplo sus análisis de Dos exclusivas del hombre, que no creo que sean confesiones profesionales, sino análisis fenomenológicos sobre el ser humano.

\section{LA ACTITUD DE GAOS SOBRE ORTEGA Y SU FILOSOFÍA}

Y ya paso al tercer punto, que será breve, porque no tiene otro objetivo que incitar y motivar a leer tanto la presentación del recopilador y editor del libro como los textos de Gaos sobre Ortega. Y digo esto porque la evaluación de los textos de Gaos sobre Ortega es una tarea pendiente. También José Lasaga la deja pendiente, como no podía ser menos, pues es mucha la tarea que en adelante tenemos que hacer.

Pero sí quiero subrayar un punto, que también lo señala el editor en su introducción. Si uno lee los textos hasta los comentarios a los póstumos de Ortega, en concreto, los comentarios al libro sobre Leibniz y a Qué es filosofía, notaremos claramente dos grupos con dos talantes muy distintos. Todos los primeros, incluido en ellos el parágrafo que le dedica en las Confesiones profesionales, están movidos por un tono extraordinariamente positivo y de reconocimiento a Ortega. Como titula uno de los textos en torno a la muerte de Ortega, son una "Salvación de Ortega". El interés de Gaos es salvar a Ortega, comprenderlo y centrarlo en lo que Gaos piensa que es lo fundamental de Ortega, a veces contra el miso 
Ortega. La prueba de este tono afectivo positivo es la dedicatoria con que Gaos envía a la familia Ortega el libro, en el que recoge esos ensayos, publicado en 1957 con el mismo título que aparece en el tomo IX. La dedicatoria dice: "para Da Rosa Spottorno de Ortega y Gasset y para Miguel, Soledad y José Ortega Spottorno, en homenaje a la memoria de D. José Ortega y Gasset, y en reiteración de un discipulado siempre reconocido con la mayor admiración y gratitud y esencial fidelidad al grande e inolvidable maestro. Ciudad Universitaria de México, 18 de octubre de 1957" (tomo IX, 33).

Otro es el tono de los comentarios a los dos libros póstumos, publicados a finales de la década de los cincuenta, La idea de principio en Leibniz, al que, de los años 1960 a 1962, dedica Gaos tres textos, y Qué es filosofía, de la misma época, al que dedica un largo ensayo. Mientras el tono de los primeros artículos o trabajos es de salvar a Ortega, el de los segundos es lo contrario, que Ortega en esos textos intenta llevar a cabo aquello que no puede dar, una filosofía sistemática.

Con esta publicación que hoy presentamos se nos da un tema de estudio para los próximos años extraordinariamente interesante, tanto para evaluar a Gaos como su propia visión de Ortega. Yo iba a extenderme en el texto sobre Que es filosofía, pero supondría alargarme demasiado, por lo que quiero dejar solamente un apunte que ya he anunciado antes, lo que la fecha de 1958 representa en Gaos. No quiero decir que su precaria salud, que estalló con el infarto de ese año, sea la explicación de la evaluación negativa de Ortega que está presente en estos años. Pero sí quiero dar una perspectiva sobre el tono afectivo en que se sumerge Gaos y que le va a teñir sus últimos años de vida, hasta su muerte. $Y$ yo creo que es el infarto el que lo determina. Yo diría que Gaos no se resigna con su enfermedad, y se obsesiona con la necesidad de exponer su propia filosofía, tal como lo indica José Lasaga, porque parece que su vida se acorta. Pero esa obsesión sospecho que va a la par con una actitud afectiva negativa respecto a lo que hacen algunos de los que le rodean. $Y$ voy a citar algunos datos que dejar vislumbrar ese tono, que yo llamaría un poco de "cascarrabias", en que parece estar sumergido Gaos desde esa fecha. Voy a citar cuatro hechos, a los que añadiré los comentarios de Vera Yamuni.

Primero, el año 1959 se organiza un seminario sobre la actualidad de Husserl con motivo del centenario de su nacimiento. En el seminario participan sus discípulos más comprometidos con la fenomenología como Luis Villoro y Alejandro 
Rossi. Eligen para comentar La filosofía como ciencia rigurosa de Husserl. Para la publicación de las comunicaciones Gaos escribe un texto, que es todo un modelo de insultos a Husserl, como nunca los había pronunciado. ¿Es una reacción al compromiso positivo de sus alumnos? Así lo creo porque termina llamándoles, y es el segundo dato, "alumnos rebeldes". Tiene conciencia de que sus alumnos se le están yendo. Es lo que terminará reconociendo Rossi en el retrato sobre Gaos que publica en la Antología y que, de modo muy significativo, no se ha recogido en la reedición que se ha hecho de esa antología en el Fondo de Cultura Económica.

El tercer dato es el Simposio sobre el mundo de la vida, que se lleva a cabo en el seno del Congreso Internacional de Filosofía, de 1963, que es un gran acontecimiento intelectual para México. El Simposio se hace para evaluar La crisis, que se había publicado unos años antes. En ese Simposio se insiste en tres cosas, la subjetividad trascendental que aparece en La crisis es corporal, histórica e individual, tres cosas que van directamente contra la opinión de Gaos sobre la naturaleza de la subjetividad trascendental husserliana, que él opone a las heideggeriana y orteguiana, a las que se suma Gaos. En La crisis, por el contrario, aparece esa subjetividad como la defendida por Husserl, lo que invalidaba radicalmente la interpretación de Gaos, como antes había invalidado la interpretación de Ortega, lo que este resolvió fácilmente, pero también de modo fácilmente falsable, diciendo que La crisis procedía de Fink.

Hay que leer los comentarios de Gaos sobre los participantes en ese simposio, que, todos, leen a Husserl desde La crisis. El texto de Gaos para ese Congreso es interesantísimo y por lo demás ilustrativo de la contrariedad que le supuso la publicación de La crisis. En el tomo $X$ se publicaron todos esos materiales, deliciosos para comprender el tono afectivo con que Gaos recibe esos escritos.

El cuarto dato es el incidente que, en abril de 1966, hubo en la Universidad con el Rector por parte de un grupo de alumnos, que irrumpieron en una Junta, insultaron al Rector y le exigieron la dimisión. El nuevo Rector no expulsó a esos alumnos como exigía Gaos, y éste se fue de la Universidad, recluyéndose académicamente sólo en el Colegio de México, que había asumido la tarea de la Casa de España en México, donde fue nombrado profesor especial, cargo que mantuvo hasta su muerte. 
Por otro lado, si se leen los comentarios de Vera Yamuni sobre esos últimos años de Gaos, se ve que era una persona un tanto atormentada. Sus rezos continuos, a quien fuere, indican una situación personal al menos llamativa y anómala. En mi opinión, este tono afectivo, que le adviene presumiblemente con motivo del primer infarto, le hace renovar la opinión con que, ya en su juventud, había prejuzgado a Ortega, y que Lasaga cita de la carta del 7 de agosto de 1923, cuando Gaos tenía 23 años, en la que Gaos dice que "Ortega no es capaz de escribir un Tratado". Es la idea con que aborda Gaos las obras póstumas de Ortega, el libro sobre Leibniz y Qué es filosofía, para mostrar que ninguna de las dos es un "tratado" de filosofía.

Nuestra tarea, facilitada por esta publicación que ahora presentamos, es estudiar a fondo los argumentos de Gaos, y con ellos estudiar a fondo la filosofía de Ortega. 